\title{
PERBEDAAN TINGKAT IMUNITAS BAYI 0 - 12 BULAN YANG DIBERIKAN ASI EKSKLUSIF DAN SUSU FORMULA DI RSIA PRIMA HUSADA SIDOARJO
}

\author{
Nyna Puspitaningrum, SST ${ }^{(1)}$, Retno Setyo Iswati, SST ${ }^{(2)}$ \\ Prodi D-III Kebidanan Universitas PGRI Adi Buana Surabaya \\ retnosetyoiswati@gmail.com
}

\begin{abstract}
ABSTRAK
Menyusui adalah suatu cara yang tidak ada duanya dalam memberikan makanan yang ideal bagi pertumbuhan dan perkembangan bayi yang sehat. Meskipun menyusui bayi sudah menjadi budaya indonesia, namun praktek pemberian Air Susu Ibu (ASI) masih buruk. Buruknya pemberian ASI ini di picu oleh promosi susu formula diberbagai media dan sarana pelayanan kesehatan (SPK). Menganalisis perbedaan tingkat imunitas bayi usia 0-12 bulan yang di beri ASI Eksklusif dan susu formula. Jenis penelitian yang di lakukan adalah penelitian analitik yang bersifat retrospektif. Lokasi penelitian ini dilaksanakan di RSIA Prima Husada Sidoarjo. Penelitian dilaksanakan pada 3-6 Oktober 2011. Populasi dalam penelitian ini adalah responden yang memenuhi kriteria inklusi. Penelitian dilakukan dengan menggunakan simple random sampling dengan besar sampel,dimana variabel independen adalah tingkat imunitas bayi 0-12 bulan, dan variabel dependen ASI Eksklusif dan susu formula. Instrumen yang di gunakan adalah kuisioner. Dari hasil penelitian di dapatkan perbedaan tingkat imunitas bayi usia 0-12 bulan yang di beri ASI Eksklusf dan susu formula,sebagian kecil yaitu 14 orang yang di beri ASI Eksklusif mengalami sakit dan sebagian besar tidak mengalami sakit yaitu 16 orang dari 30 peserta responden. Data yang terkumpul dianalisis dengan menggunakan uji statistik chi-square program statistik SPSS 16 dengan tingkat $\rho \leq 0,05$.Dari analisis dengan uji chi-square di peroleh $\rho<\alpha(0,01<0,05)$. Hal ini berarti terdapat perbedaan antara tingkat imunitas bayi usia 0-12 bulan yang di beri ASI Eksklusif dan susu formula. Berdasarkan hasil tersebut diatas, maka dapat disimpulkan pentingnya upaya meningkatkan kesadaran bahwa betapa pentingnya kandungan gizi dari ASI untuk daya imunitas bayi 0-12 bulan daripada susu formula
\end{abstract}

Kata kunci : Tingkat imunitas, ASI Eksklusif, susu formula, bayi usia 0-12 bulan

\section{PENDAHULUAN}

Menurut WHO (World Health

Oranization/Badan Kesehatan Dunia) ASI

Eksklusif adalah pemberian Air Susu Ibu

saja tanpa cairan tambahan cairan lain

hingga bayi berusia 6 bulan. Produksi ASI di nyatakan cukup sebagai makanan tunggal untuk pertumbuhan bayi yang normal sampai usia 6 bulan. Menyusui adalah suatu cara yang tiada duanya dalam memberikan makanan yang ideal bagi pertumbuhan dan perkembangan bayi yang sehat serta mempunyai pengaruh biologis 
dan kejiwaan yang unik terhadap kesehatan ibu dan bayi,di harapkan setelah melahirkan ibu dapat menerapkan pemberian ASI Eksklusif dan memahami bahwa pemberian ASI meningkatkan daya tahan tubuh dan kecerdasan bayi.

\section{Bagi bayi, ASI merupakan} makanan yang paling sempurna di mana kandungan gizi sesuai kebutuhan untuk pertumbuhan dan perkembangan yang optimal. ASI juga mengandung zat untuk perkembangan kecerdasan, zat kekebalan (mencegah dari berbagai penyakit) dan dapat menjalin hubungan cinta kasih antara bayi dengan ibu. Manfaat menyusui bagi ibu tidak hanya menjalin kasih sayang, tetapi terlebih dapat dapat mengurangi perdarahan setelah melahirkan, mempercepat pemulihan kesehatan ibu, menunda kehamilan, mengurangi resiko terkena kanker payudara, dan merupakan kebahagiaan tersendiri bagi ibu.
Angka kematian bayi (AKB) yang masih tinggi yaitu 35/1000 kelahiran hidup pada tahun 2007 menjadi tolak ukur penilaian kesejahteraan suatu daerah wilayah atau negara. Di asumsikan bayibayi tersebut meninggal karena berbagai penyebab kematian. Penyebab kematian bayi masih bisa di perbaiki sehingga tidak menderita berkepanjangan dan berakhir dengan kematian.

Pemberian ASI Eksklusif dapat mempercepat penurunan angka kematian bayi dan sekaligus meningkatkan status gizi bayi yang pada akhirnya akan meningkatkan status gizi masyarakat menuju tercapainya Sumber Daya Manusia yang memadai. Masalah pelaksanaan ASI Eksklusif adalah masalah yang sangat memprihatinkan,data Survey Demografi Kesehatan Indonesia (SDKI) Tahun 2007 menjelaskan bahwa ibu-ibu yang memberikan ASI Eksklusif kepada bayinya mencapai $67 \%$ sedangkan targetnya $80 \%$. 
Hasil survey membuktikan masih sedikit bayi yang menerima ASI Eksklusif karena masalah pada ibu turut memicu kegagalan menyusui, pada sebagian ibu yang tak memahami masalah tersebut, kegagalan cenderung di anggap sebagai problem pada bayi saja, padahal persoalan yang terjadi selama menyusui dapat di mulai sebelum masa persalinan, setelah persalinan dini (prematur), sampai sesudah persalinan lanjut. Problem yang muncul dalam hubunganya dengan persalinan itu, antara lain puting susu datar atau terbenam, lecet, payudara bengkak, bahkan meradang, sindrom ASI kurang, dan persoalan pada ibu yang bekerja di luar rumah. Masalah menyusui juga bisa di akibatkan oleh keadaan khusus seperti ibu yang melahirkan dengan caesar, sakit, penderita infeksi hepatitis maupun HIV/AIDS.

$$
\begin{aligned}
& \text { Pemberian ASI di Indonesia belum } \\
& \text { di laksanakan sepenuhnya.Upaya } \\
& \text { meningkatkan perilaku menyusui pada } \\
& \text { bayi yang memiliki bayi khususnya ASI }
\end{aligned}
$$

Eksklusif

dirasa

masih

kurang.Permasalahanya yang utama adalah faktor sosial budaya, kesadaran atas pentingnya ASI, pelayanan petugas kesehatan yang belum sepenuhnya mendukung PP-ASI.Gencarnya promosi susu formula dan ibu bekerja.

Berdasarkan data profil Dinas Kesehatan Jawa Timur tahun 2010 didapatkan cakupan pemberian.ASI Eksklusif selama 6 bulan di tingkat provinsi naik dari $31,21 \%$ (2010) menjadi 61,52 \% (2011). Dinas Kesehatan Provinsi Jawa Timur telah melakukan berbagai program dan kegiatan dalam rangka meningkatkan cakupan pemberian ASI Eksklusif pada bayi antara lain adalah memberikan pelatihan konselor ASI/ Menyusui.

\section{METODE}

Penelitian yang dilakukan adalah penelitian Observasional Analitik. Desain rancang bangun penelitian ini adalah rancang bangun 
studi retrospektif (riwayat yang lalu), dilaksanakan di Ruang KIA RSIA Prima Husada Sidoarjo pada bulan juni s/d oktober 2011. Populasi dalam penelitian ini adalah seluruh bayi yang berada di RSIA Prima Husada Sidoarjo bulan Juni - Oktober 2011 yang berjumlah 30orang. Dan analisa data dilakukan uji Chi Square. Uji ini digunakan untuk mengukur tingkat eratnya hubungan antaraa 2 variabel yang berskala nominal.

Rumus : chi kuadrat $\left(\mathrm{X}^{2)}=\sum \underline{(\mathrm{fo}-\mathrm{fh})^{2}}\right.$

fh

\section{HASIL PENELITIAN}

Tabel Distribusi Frekuensi Tingkat Imunitas Bayi 0-12 bulan Yang Diberi ASI Eksklusif di RSIA Prima HusadaWaru Sidoarjo 3 dan 6 Oktober 2011.

\begin{tabular}{l|l|l}
\hline $\begin{array}{c}\text { Tingkat Imunitas } \\
\text { Bayi 0-12 Bulan } \\
\text { yang di beri ASI } \\
\text { Eksklusif }\end{array}$ & Jumlah & $\begin{array}{c}\text { Prosentase } \\
(\%)\end{array}$ \\
\hline Sakit & 5 & 33,4 \\
\hline Tidak Sakit & 10 & 66,6 \\
\hline Jumlah & 15 & 100 \\
\hline Sumber : Data Primer, 2011
\end{tabular}

Dari tabel diatas diperoleh hasil sebagian besar bayi yang diberi ASI
Eksklusif yang tidak mengalami sakit ada 5 bayi $(33,4 \%)$ dan sebagian kecil yang mengalami sakit ada 10 bayi $(66,6 \%)$.

Sistem imunitas bayi telah ada sejak lahir namun baru sebagian yang berkembang. Hal ini berarti lebih rentan pada tahun-tahun pertama kehidupanya. Komposisi ASI juga selalu berubah untuk memenuhi kebutuhan bayi. ASI sangat mudah di cerna bayi sehingga bayi tidak terganggu kesehatanya.

Dengan demikian bayi yang di beri

ASI Eksklusif dan mengalami sakit kemungkinan terjadi karena kurangnya rasa percaya diri ibu, kurangnya pengetahuan, sikap, dan pengalaman ibu bayi terhadap pentingnya pemberian ASI Eksklusif kepada bayinya. Ibu yang kembali bekerja juga merupakan faktor dimana ibu tidak memberikan ASI kepada bayinya. Dukungan dari keluarga juga sangat berpengaruh dalam pemberian ASI oleh ibunya, sehingga bayi yang di beri ASI Eksklusif sejak pertama maka dia 
akan lebih mendapatkan daya kekebalan tubuh atau imunitas yang lebih optimal. Bayi yang telah mendapatkan ASI Eksklusif sejak lahir maka bayi akan tidak mudah sakit.

Tabel Distribusi Frekuensi Tingkat ImunitasBayi 0-12 Bulan yang Diberi Susu Formula di RSIA Prima HusadaSidoarjo 3 dan 6 Oktober 2011.

\begin{tabular}{l|l|l}
$\begin{array}{l}\text { Tingkat } \\
\text { Imunitas Bayi } \\
\text { Usia 0-12 } \\
\text { Bulan yang } \\
\text { Diberi Susu } \\
\text { Formula }\end{array}$ & Jumlah & $\begin{array}{l}\text { Prose } \\
\text { ntase } \\
(\%)\end{array}$ \\
\hline Sakit & 9 & 60 \\
\hline Tidak Sakit & 6 & 40 \\
\hline Jumlah & 15 & 100
\end{tabular}

Sumber : Data Primer, 2011

Dari tabel diatas diperoleh hasil bahwa sebagian besar bayi yang menggunakan susu formula mengalami sakit sebanyak 9 bayi dengan prosentase
(90\%), sedangkan sebagian kecil bayi yang menggunakan susu formula mengalami tidak sakit sebanyak 6 bayi dengan prosentase $(40 \%)$.

Dengan demikian bayi yang di beri susu formula dan mengalami sakit kemungkinan terjadi karena kurangnya rasa percaya diri ibu bahwa ASI nya kurang. Bisa juga di karenakan oleh kebersihan tempat botol atau dot yang kurang bersih yang mengakibatkan kuman, bakteri masuk ke dalam botol dan menimbulkan penyakit sehingga daya kekebalan imunitas bayi menjadi menurun. Susu formula merupakan media yang baik bagi pertumbuhan bakteri, oleh karena itu kontaminasi mudah terjadi terutama dalam persiapan dan pemberian kurang memperhatikan segi kebersihan. Dan masih rendahnya tingkat kesadaran ibu bayi yang kurang memperhatikanya sehingga bayi mudah terserang penyakit. 
Tabel Tabulasi SilangTingkat Imunitas Bayi Usia 0-12 Bulan yang Diberi ASI Eksklusif dan Susu Formula di RSIA Prima Husada Sidoarjo 3 dan 6 Oktober

Sumber : Data Primer, 2011

Dari tabel diatas Menunjukkan bahwa dari

30 responden yang menggunakan ASI

Eksklusif sebagian kecil responden tingkat

imunitas yang memakai ASI Eksklusif dan

mengalami sakit sebanyak 5 bayi $(33,4 \%)$

dan sebagian besar tingkat imunitas yang

memakai ASI Ekslusif dan tidak

mengalami sakit sebanyak 10 bayi $(66,6 \%)$

Berdasarkan data yang dianalisadengan perhitungan komputerisasi menggunakan Stastical Product And Service (SPSS) Versi 16,0 For Windows menggunakan uji chi-square dengan taraf signifikasi atau derajat kemaknaan $\alpha=$ 0,05 secara SPSS atau $\rho<\alpha 0,01<0,05$ dengan demikian bearti Ho ditolak H1 diterima. Hal ini menunjukkan bahwa ada perbedaan antara tingkat imunitas bayi yang diberi ASI Eksklusif dan susu formula di RSIA Prima HusadaSidoarjo.
Dari hasil uji chi square jugadidapatkan nilai $\rho$ 0,01, dimana $\rho<\alpha$ yaitu $0,01<$

ASI

Eksklusif
\&Susu
Formula

ASI Susu Total Eksklusif Formula

$\begin{array}{lcccccc}\quad \text { Tingkat } & \mathbf{N} & \boldsymbol{\%} & \mathbf{N} & \mathbf{\%} & \mathbf{N} & \boldsymbol{\%} \\ \begin{array}{l}\text { Imunitas } \\ \text { Sakit }\end{array} & 5 & 33,4 & 9 & 60 & 14 & 100 \\ \text { Tidak Sakit } & 10 & 66,6 & 6 & 40 & 16 & 100 \\ \text { Total } & 15 & 100 & 15 & 100 & 30 & 100 \\ \quad 0,05 \quad \text { maka } & \text { Ho } & \text { ditolakdan } & \text { H1 } & \end{array}$

diterimaartinya ada perbedaan tingkat imunitas bayi yang diberi ASI Eksklusif dan susu formula

Dari hasil penelitian diatas dan yang di analisa, bahwa bayi yang telah diberi ASI Eksklusif ternyata bayi tersebut daya kekebalannya lebih baik dan tidak mudah mengalami sakit karena tingkat imunitasnya lebih kuat, sedangkan bayi yang telah diberi susu formula ternyata tingkat imunitasnya lebih rendah daripada bayi yang telah di beri ASI karena daya kekebalan tubuhnya rendah dan bayi sering mengalami sakit. Bayi yang telah diberi ASI tumbuh kembangnya lebih 
optimal dan bayi yang diberi susu formula

tumbuh kembangnya lebih lambat. Dengan

demikian ada perbedaan antara tingkat imunitas bayi usia 0-12 bulan yang diberi

ASI Eksklusif dan susu formula. 